\title{
BIOMETRIA DE FRUTOS E SEMENTES, GERMINAÇÃO E DESENVOLVIMENTO INICIAL DE BARBATIMÃO (Stryphnodendron adstringens)
}

\author{
Valéria Lúcia de Oliveira Freitas ${ }^{1}$, Fabrícia Pena Viegas ${ }^{2}$, Renata de Melo Ferreira Lopes ${ }^{3}$ \\ ${ }^{1}$ Bióloga, Dr ${ }^{\mathrm{a}}$., Gerência Ambiental, Centro de Tecnologia Senai Cetec, Belo Horizonte, MG, Brasil - valolifreitas@ hotmail.com \\ ${ }^{2}$ Bióloga, Fundação Cetec, Belo Horizonte, MG, Brasil - fabriciaviegas@ hotmail.com \\ ${ }^{3}$ Bióloga, Dr ${ }^{\mathrm{a}}$., Fundação Cetec, Belo Horizonte, MG, Brasil - renatademeloferreira@ yahoo.com.br
}

Recebido para publicação: 10/06/2013 - Aceito para publicação: 24/10/2013

\begin{abstract}
Resumo
Stryphnodendron adstringens é uma árvore de ampla distribuição no cerrado. Sua casca apresenta alto teor de tanino e é intensamente explorada, devido à sua ação adstringente. Os objetivos deste trabalho foram identificar características biométricas de frutos e sementes e avaliar o efeito da temperatura, escarificações e armazenamento na germinação de suas sementes, assim como avaliar o crescimento inicial das mudas em diferentes condições de sombreamento. O comprimento, a largura e a espessura variaram de 48,1 a $97,0 \mathrm{~mm}$, de 10,1 a $16,9 \mathrm{~mm}$ e de 6,4 a 19,6 mm para os frutos e de 3,7 a 10,0 mm, 3,1 a 5,7 mm e 1,6 a 4,4 mm para as sementes. O número médio de sementes por fruto foi de 8,2 $\pm 2,5$, sendo 39\% de sementes danificadas. A massa de 1000 sementes foi de 68,4 g. A escarificação mecânica foi o tratamento mais eficiente na superação da dormência, aumentando a porcentagem e o índice de velocidade de germinação. A faixa ótima de germinação foi de 25 a $35^{\circ} \mathrm{C}$ e as sementes permaneceram viáveis após oito meses de armazenamento. Os resultados apontaram que a espécie é heliófita, de crescimento lento, podendo ser adequada ao plantio em áreas degradadas.

Palavras-chave: Fabaceae; espécie arbórea; dormência; viabilidade.
\end{abstract}

\begin{abstract}
Fruit and seed biometry, seeds germination and initial growth of barbatimão (Stryphnodendron adstringens). Stryphnodendron adstringens is a tree widely distributed in the Cerrado. Its bark has high tannin content and is heavily exploited due to its astringent action. This research aims to identify biometric characteristics of fruits and seeds, and also assess the effect of temperature, scarifications and storage on germination of its seeds as well as evaluate the initial seedling growth under different conditions of shading. Was also evaluated the seedling response submitted to two levels of shading ( 0 and 50\%) in nursery conditions. Length, width and thickness ranged from 48.1 to $97.0 \mathrm{~mm}$, from 10.1 to $16.9 \mathrm{~mm}$ and from 6.4 to $19.6 \mathrm{~mm}$ for fruits and from 3.7 to $10.0 \mathrm{~mm}, 3.1$ to $5.7 \mathrm{~mm}$, and 1.6 to 4.4 $\mathrm{mm}$ for seeds. The average number of seeds per fruit was $8.2 \pm 2.5,39 \%$ damaged seeds. The weight of 1000 seeds was $68.4 \mathrm{~g}$. Mechanical scarification was the most efficient in breaking dormancy, increasing the percentage and germination speed index. The optimum range of germination rate was 25 to $35^{\circ} \mathrm{C}$ and they remained viable after eight months of storage. The results revealed that the species is heliophytic, has slow growth, and is appropriate for planting in degraded areas.

Keywords: Fabaceae; tree species; dormancy; viability.
\end{abstract}

\section{INTRODUÇÃO}

O cerrado é a formação savânica com a maior diversidade vegetal do mundo (GUARIM NETO; MORAIS, 2003; REZENDE; FELFILI, 2004). Suas espécies são amplamente utilizadas por serem alimentícias, medicinais, ornamentais, forrageiras, apícolas e produtoras de madeira, cortiça, fibras, óleo e tanino (ALMEIDA et al., 1998). Contudo, esse extrativismo ocorre sem um manejo adequado (BORGES FILHO; FELFILI, 2003). Diante desses fatos e por estar incluído na lista dos 34 ecossistemas mais ameaçados do planeta, o cerrado necessita de medidas urgentes para a sua preservação (MITTERMEIER et al., 2004). 
Stryphnodendron adstringens (Mart.) Coville é uma árvore comum no cerrado, com ampla distribuição geográfica, desde o Pará, passando pelo Planalto Central, até o norte do Paraná (FELFILI et al., 1999). Sua casca contém alto teor de tanino, que apresenta ação anti-inflamatória e adstringente (LISBOA et al., 2006), sendo muito utilizada nos curtumes, na fabricação de fibras e material corante de cor vermelha (BRANDÃO, 1992). Também é uma das espécies florestais de maior destaque quanto ao valor econômico, possuindo uma cadeia de mercado consolidada. Entretanto, a atividade extrativista apresenta indícios de declínio (BORGES FILHO; FELFILI, 2003), especialmente devido à expansão da fronteira agrícola desse importante bioma, promovendo a sua degradação e fragmentação (RATTER et al., 1997). Caso não sejam tomadas medidas urgentes para a conservação, manejo e protocolos de extração da casca, a espécie corre risco de extinção (BORGES FILHO; FELFILI, 2003), principalmente quando considerado o ritmo acelerado de degradação e fragmentação do cerrado.

A obtenção de dados ecofisiológicos e silviculturais de espécies nativas auxilia na escolha correta das espécies vegetais em programas de recuperação de áreas degradadas (LABOURIAU, 1983) e na definição de modelos de manejo sustentável das espécies florestais nativas de interesse econômico e ambiental. S. adstringens é uma espécie que pode ser utilizada com esse objetivo, por apresentar boa capacidade de adaptação em áreas degradadas onde houve o decapeamento de camadas superficiais do solo (LINS et al., 2002), além de apresentar alta taxa de sobrevivência em programas de revegetação (PARRON et al., 2000). Também possui a capacidade de aumentar a fixação biológica do nitrogênio, favorecendo mecanismos de sucessão vegetal e revitalização do solo, representando uma economia no uso de fertilizantes (RESENDE; KONDO, 2001).

Entre as leguminosas, é comum a presença de dormência nas sementes, devido ao tegumento duro e impermeável à água (RIZZINI, 1997; BASKIN; BASKIN, 1998), o que prejudica as atividades de viveiro (MELO et al., 1998). Nesse caso, estudos de superação de dormência têm grande importância prática, pois permitem a utilização de tratamentos apropriados para se obter uma produção uniforme de mudas.

Considerando o alto grau de impacto ambiental sofrido pelo bioma cerrado e a utilização intensa e indiscriminada da casca de $S$. adstringens, o objetivo deste trabalho foi identificar características biométricas de frutos e sementes e avaliar o efeito da temperatura, de escarificações e do armazenamento na germinação de suas sementes, assim como avaliar o crescimento inicial das mudas em diferentes condições de sombreamento.

\section{MATERIAL E MÉTODOS}

\section{Coleta e beneficiamento de frutos e armazenamento de sementes}

Os frutos maduros de $S$. adstringens, provenientes de 16 matrizes marcadas com distância mínima de 30 metros entre si, foram coletados em uma mesma população no município de Papagaio/MG $\left(19^{\circ} 18^{\prime} \mathrm{S}\right.$ e $\left.44^{\circ} 36^{\prime} \mathrm{W}\right)$, em agosto/2002 e agosto/2003. As sementes foram extraídas manualmente e acondicionadas em sacos de papel, em temperatura ambiente, até o início do experimento. No caso dos frutos coletados em 2002, após o beneficiamento, suas sementes foram acondicionadas em sacos de papel e armazenadas em refrigerador $\left(5-9^{\circ} \mathrm{C}\right)$ por oito meses, até o início do experimento.

\section{Biometria de frutos e sementes}

Para o estudo das características morfométricas, foram utilizados 100 frutos e 100 sementes recém-coletados tomados aleatoriamente de uma amostra composta. O comprimento, a largura e a espessura dos frutos e das sementes foram medidos com paquímetro (precisão de $0,01 \mathrm{~mm}$ ). $\mathrm{O}$ comprimento dos frutos, sem o pedúnculo, foi medido da base até o ápice, e a largura e a espessura medidas na linha mediana dos frutos e sementes. Os valores de massa fresca dos frutos e das sementes foram obtidos utilizando-se balança analítica (precisão de 0,001 g). Também foi registrado o número de sementes intactas, abortadas e/ou danificadas. A massa de mil sementes foi determinada pela média de 10 repetições de 100 sementes.

As sementes tiveram o conteúdo de água determinado pelo método da estufa, com temperatura controlada de $80{ }^{\circ} \mathrm{C}$. Quatro repetições de dez sementes, tomadas ao acaso, foram acondicionadas em papel alumínio e permaneceram sob aquecimento até atingir massa constante. A diferença entre a massa fresca e a massa seca das amostras foi utilizada para o cálculo da porcentagem do conteúdo de água das sementes. 


\section{Avaliação da viabilidade}

A viabilidade das sementes recém-coletas e armazenadas foi determinada pelo teste de tetrazólio. Três repetições de 25 sementes, escarificadas mecanicamente com lixa d'água na extremidade oposta ao eixo embrionário, foram imersas em solução de cloreto de trifenil tetrazólio a $1 \%$ e permaneceram no germinador por 24 horas, a $25^{\circ} \mathrm{C}$, na ausência de luz (LEDO, 1977). Posteriormente, as sementes foram lavadas em água corrente, seccionadas longitudinalmente e analisadas individualmente, externa e internamente. Foram consideradas mortas as sementes sem coloração dos embriões ou as que apresentaram mais de 50\% da estrutura do embrião sem coloração (BRASIL, 1992).

\section{Avaliação da germinação}

Foi avaliado o efeito da temperatura, da luz e do armazenamento sobre a porcentagem e o índice de velocidade de germinação. Para ambas as coletas, foram utilizadas sementes não escarificadas (grupo controle) e escarificadas: i) mecanicamente - lixa d'água $\left(\mathrm{n}^{\mathrm{o}} 120\right)$; ii) quimicamente - imersão em ácido clorídrico $35 \%$ por 20 minutos, lavagem em água corrente por 10 minutos e hidratação em água destilada por 12 horas; iii) termicamente - imersão em água a $70{ }^{\circ} \mathrm{C}$ e embebição por 12 horas fora do aquecimento. As sementes não escarificadas e as escarificadas foram submetidas a assepsia com hipoclorito de sódio a $5 \%$ por 15 minutos, seguida de lavagem em água corrente. Foram avaliadas também diferentes temperaturas: i) constante: 25 e $35^{\circ} \mathrm{C}$, em fotoperíodo de 12 horas de luz branca, e $30^{\circ} \mathrm{C}$ em ausência total de luz (somente para as sementes armazenadas); ii) alternada: $20-30^{\circ} \mathrm{C}$, em fotoperíodo de 12 horas de luz branca, sendo o período luminoso correspondente à temperatura mais elevada. Com a finalidade de avaliar a germinação em cada tratamento, foram utilizadas quatro repetições de 50 sementes, colocadas em caixas de plástico transparente com tampa, sobre papel filtro, e mantidas em germinadores. $\mathrm{O}$ delineamento experimental utilizado foi inteiramente casualizado. A germinação foi avaliada diariamente durante 28 dias, sendo consideradas germinadas as sementes que apresentaram a emissão de radícula.

Os dados obtidos foram avaliados em termos de porcentagem de germinação. Para análise do vigor das sementes, foi utilizado o Índice de Velocidade de Germinação (IVG) segundo Maguire (1962).

\section{Desenvolvimento inicial das plantas jovens}

Mudas de S. adstringens com cinco meses de idade, crescendo em sacos plásticos (10 x $15 \mathrm{~cm})$ com solo do cerrado, foram aclimatadas à sombra natural de árvores adultas, durante 30 dias. Após esse período, as mudas foram submetidas às seguintes condições: i) pleno sol, representando uma condição extrema de área degradada; e ii) casa de vegetação com cobertura lateral de sombrite verde e cobertura superior com plástico transparente, simulando condição de clareira.

O delineamento experimental foi inteiramente casualizado com 20 mudas por tratamento, onde cada muda representava uma repetição. As plantas foram regadas diariamente com o objetivo de manter as condições hídricas no nível de capacidade de retenção de água. Aos seis meses de idade foram iniciadas as mensurações das variáveis alométricas (altura, diâmetro do coleto e número de folhas), em intervalos quinzenais, durante nove meses e meio. A altura das plantas foi obtida com o auxílio de régua milimetrada, representando a distância entre o nível do solo e a gema apical, e o diâmetro ao nível do solo com o uso de paquímetro de precisão $(0,01 \mathrm{~mm})$. Após cada avaliação, foi realizada a movimentação dos indivíduos, visando à homogeneização dos fatores não controlados, como competição entre indivíduos e incidência luminosa.

\section{Tratamento estatístico}

Os dados de biometria foram avaliados com estatística básica: valor médio, desvio padrão e coeficiente de variação, sendo analisados por meio da distribuição de frequência. Os resíduos das médias das porcentagens de germinação apresentaram distribuição normal e homocedástica e foram analisados pela análise de variância (ANOVA), seguida do teste de Tukey a 5\% (ZAR, 1999), para a comparação das médias. Os dados do crescimento das mudas foram submetidos ao teste de normalidade e posteriormente ao teste $t$ de Student ( $\mathrm{p}<0,05)$.

\section{RESULTADOS E DISCUSSÃO}

\section{Biometria dos frutos e sementes}

Stryphnodendron adstringens apresentou maior número de frutos nas classes de comprimento entre 62,1 e $69,0 \mathrm{~mm}$, largura entre 11,6 e $14,5 \mathrm{~mm}$ e espessura entre 12,1 e 16,0 mm (Figura 1). Os frutos apresentaram baixo coeficiente de variação para as medidas de largura e comprimento e alto 
coeficiente de variação para o número de sementes danificadas por fruto (Tabela 1). Em relação à biometria das sementes, foi observada maior frequência nas classes de comprimento entre 7,1 e $8,0 \mathrm{~mm}$, largura entre 3,6 e 4,5 mm e espessura entre 2,6 e 3,5 mm (Figura 1).
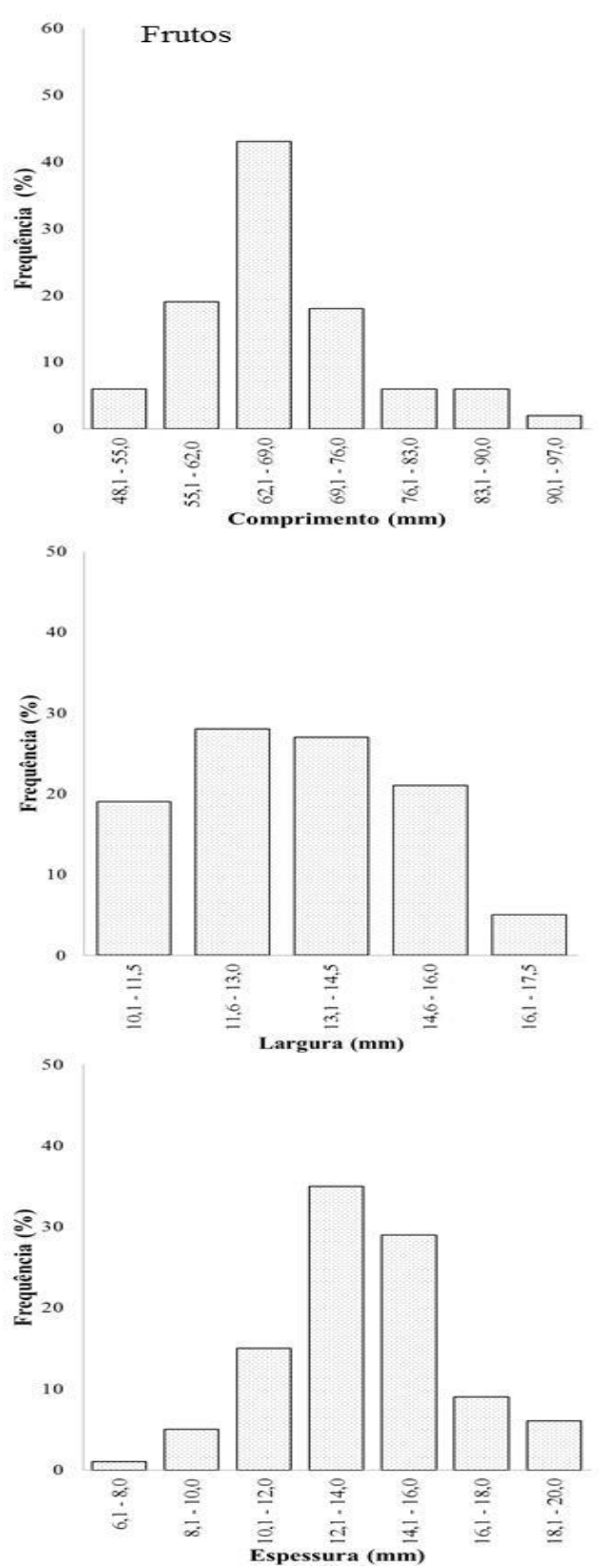
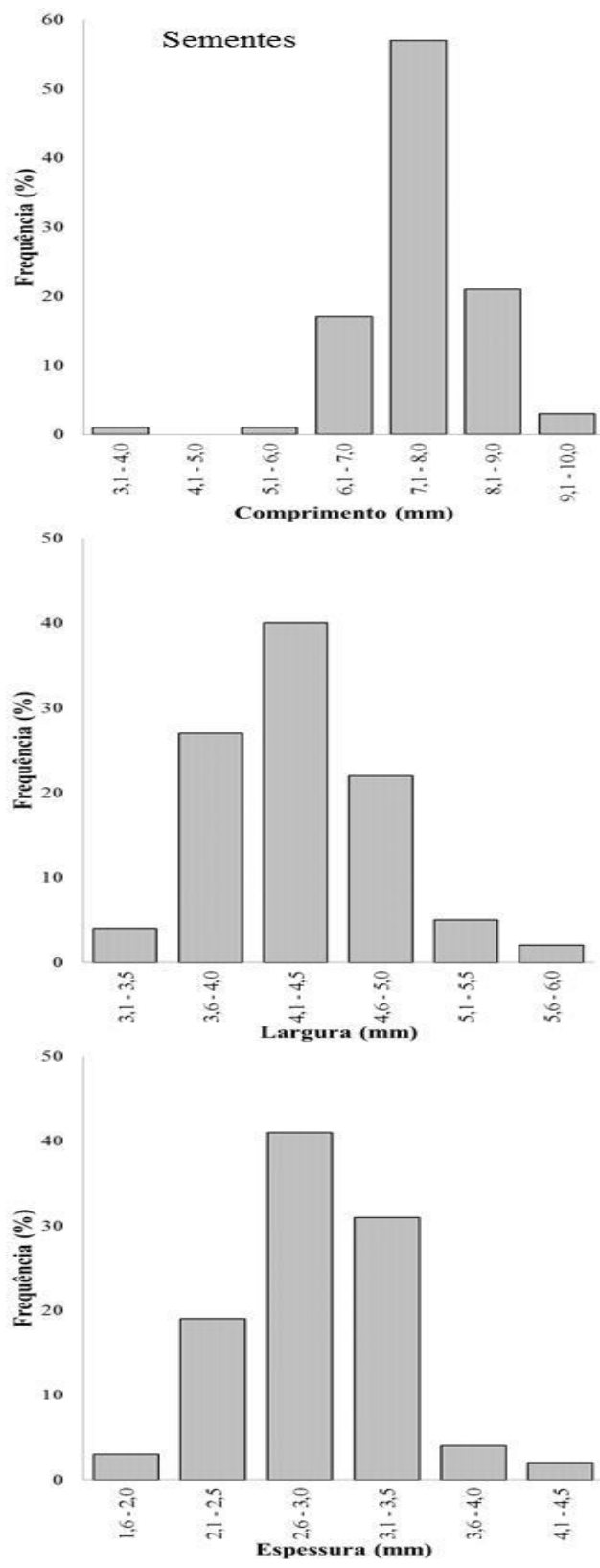

Figura 1. Frequência de distribuição para as variáveis biométricas dos frutos (barras claras) e sementes (barras escuras) de $S$. adstringens, coletados em agosto/2003 no município de Papagaio/MG $(n=100)$.

Figure 1. distribution frequency for biometric variables of fruits (light bars) and seeds (black bars) of $S$. adstringens, collected in August/2003 in the municipality of Papagaio/MG $(n=100)$. 
Todas as variáveis biométricas das sementes apresentaram baixo coeficiente de variação. A massa fresca e o conteúdo de água inicial das sementes foram, respectivamente, de aproximadamente 0,7 g e 9,7\% (Tabela 1), semelhantes aos valores relatados por Barradas e Handro (1974), de 0,9 g e de 13 a $16 \%$, para sementes coletadas em Pirassununga, SP. Os frutos e sementes de S. adstringens apresentaram variáveis biométricas similares aos dados apresentados por Kissmann (2008) em estudos realizados com populações de Chapadão do Sul/MS. Diante do exposto, podemos sugerir que as características biométricas dos frutos e sementes são mantidas entre populações de diferentes procedências. Contudo, o teor de umidade, a massa de mil sementes e o número de sementes por quilograma apresentaram valores diferentes dos encontrados por Kissmann (2008) e Martins e Nakagawa (2008), que estudaram sementes de populações provenientes de Botucatu, SP. Esse fato pode estar relacionado a diferenças quanto à época de coleta, nível de maturação dos frutos e condições climáticas dos locais de coleta.

\section{Teste de tetrazólio}

O teste de tetrazólio indicou alta viabilidade das sementes de S. adstringens, de 92\% e 95\%, respectivamente, para as sementes recém-coletadas e as armazenadas por oito meses. Esses resultados corroboram os dados de Barradas e Handro (1974), que encontraram porcentagem de germinação semelhante entre sementes recém-coletadas $(94 \%)$ e armazenadas por 12 meses (96\%). O amadurecimento dos frutos dessa espécie coincide com a época de estiagem na sua área de ocorrência. Assim, a manutenção da viabilidade por um longo período torna-se uma característica importante, pois as sementes podem compor o banco de sementes do solo, estando prontas para germinar no início da estação chuvosa, o que garantirá o estabelecimento de suas plântulas. Esses dados são importantes em se tratando do manejo da espécie, pois indicam a viabilidade da conservação das sementes ex situ por um período de pelo menos oito meses.

Tabela 1. Média, desvio padrão (DP), coeficiente de variação (CV) e intervalo de variação (IV) das variáveis biométricas e massas fresca e seca dos frutos e sementes de $S$. adstringens, coletados no município de Papagaio/MG $(n=100)$.

Table 1. Mean, standard deviation (DP), variation coefficient (CV) and variation interval (IV) of biometrics variables and fresh and dry weights of fruits and seeds of S. adstringens, collected in the municipality of Papagaio/MG $(n=100)$.

\begin{tabular}{lccc}
\hline Característica & Média \pm DP & CV (\%) & IV \\
\hline Comprimento (mm) & Fruto & & \\
Largura (mm) & $67,2 \pm 9,1$ & 13,6 & $48,1-97,0$ \\
Espessura (mm) & $13,2 \pm 1,8$ & 13,5 & $10,1-16,9$ \\
Sementes / fruto & $13,8 \pm 2,5$ & 17,8 & $6,4-19,6$ \\
Sementes danificadas / fruto & $8,2 \pm 2,5$ & 30,8 & $1,0-16,0$ \\
Massa fresca (g) & $3,2 \pm 2,4$ & 73,9 & $0,0-10,0$ \\
& $5,9 \pm 1,4$ & 24,3 & $3,2-11,0$ \\
\hline Comprimento (mm) & Sementes & & \\
Largura (mm) & $7,6 \pm 0,8$ & 10,1 & $3,7-10,0$ \\
Espessura (mm) & $4,3 \pm 0,5$ & 11,4 & $3,1-5,7$ \\
Massa fresca (g) & $2,9 \pm 0,5$ & 16,2 & $1,6-4,4$ \\
Massa seca (g) & $0,7 \pm 0,0$ & 5,5 & $0,7-0,8$ \\
Teor de umidade (\%) & $0,7 \pm 0,0$ & 6,1 & $0,6-0,7$ \\
Massa de mil sementes (g) & $9,7 \pm 0,0$ & 1,0 & $8,5-12,7$ \\
$\mathrm{~N}^{\circ}$ de sementes por quilograma (s/kg) & & 68,4 & \\
\hline
\end{tabular}

\section{Germinação}

Houve germinação das sementes de $S$. adstringens com e sem luz, nas temperaturas de 20 a $35^{\circ} \mathrm{C}$ (Tabela 2), não sendo fotossensíveis, conforme relatado por Barradas e Handro (1974). Em geral, as espécies florestais nativas do cerrado apresentam sementes que são indiferentes à presença de luz 
quando expostas em condições ótimas de germinação (MELHEM, 1975; JOLY; FELIPPE, 1979; SILVA; FELIPE, 1986; ARRIGONI-BLANK et al., 1997; AGUIAR et al., 2005).

Também foi observada a presença de dormência tegumentar, sendo a escarificação mecânica um método eficiente para promover a germinação das sementes de $S$. adstringens (Tabela 2). Essa é uma característica presente na maioria das espécies de leguminosas (POPINIGIS, 1977; REIS; MARTINS, 1989) e relatada também para as sementes de S. adstringens (BARRADAS; HANDRO, 1974). As sementes escarificadas mecanicamente apresentaram valores significativamente superiores de porcentagem e índice de velocidade de germinação em todos os tratamentos (Tabelas 2 e 3). A quebra da dormência via escarificação mecânica é citada como sendo um método eficiente e seguro para as sementes de leguminosas (BARRADAS; HANDRO, 1974; RODRIGUES et al., 1990; MIRANDA, 1999; CRUZ et al., 2001; FIRETTI, 2001).

No grupo-controle, a porcentagem de germinação observada variou de 10 a 23,5\% e de 10 a $16 \%$, para as sementes recém-coletadas e armazenadas, respectivamente (Tabela 2). Esses resultados foram semelhantes aos encontrados por Kissmann (2008), estudando populações de S. adstringens de Chapadão do Sul (MS), e por Dignart et al. (2005), para populações de Cuiabá (MT). Contudo, Barradas e Handro (1974) relataram valores de $60 \%$ e $57 \%$ para sementes intactas recém-coletadas e armazenadas, respectivamente, provenientes do município de Pirassununga (SP). Martins et al. (2008) relatam valores inferiores, variando de 6 a $10 \%$, para populações de Botucatu (SP). As diferenças encontradas podem indicar possíveis diferenças metodológicas, diferente número de matrizes, diferenças genéticas das populações, diferenças no grau de amadurecimento dos frutos e sementes e/ou variações ambientais.

A escarificação térmica, para o grupo das sementes recém-coletadas, elevou significativamente a porcentagem de germinação em relação ao controle em temperatura alternada de $20-30{ }^{\circ} \mathrm{C}$ (Tabela 2). Nas demais temperaturas não foram observadas diferenças significativas entre os tratamentos, controle e água. Os valores encontrados são superiores aos reportados por Kissmann (2008), que relatou valores semelhantes aos apresentados pelas sementes armazenadas no presente trabalho, e por Martins e Nakagawa (2008), ambos utilizando a água a $100{ }^{\circ} \mathrm{C}$. A escarificação térmica não foi eficiente na superação da dormência tegumentar, pois apresentou desempenho similar ao grupo controle e inferior à escarificação mecânica com lixa.

A escarificação química, para as sementes recém-coletadas, superou parcialmente a dormência na temperatura de $35^{\circ} \mathrm{C}$. Quanto às sementes armazenadas, foi observada uma diminuição na taxa de germinação em todas as temperaturas (Tabela 2). A utilização de ácido sulfúrico por 20 a 40 minutos também não foi um procedimento eficaz para superar a dormência dessas sementes, conforme relatado na literatura (DIGNART et al., 2005; KISSMANN, 2008). Contudo, aumentando o tempo de tratamento com o ácido sulfúrico para 60 minutos, Martins e Nakagawa (2008) obtiveram porcentagens de germinação variando de 85,8 a $89,3 \%$.

Tabela 2. Porcentagem de germinação de sementes de $S$. adstringens recém-coletadas e armazenadas, por oito meses, submetidas a temperaturas constantes e alternadas (média \pm desvio padrão).

Table 2. Germination percentage of seeds of $S$. adstringens newly collected and stored, for eight months, under constant and alternating temperatures (mean \pm standard deviation).

\begin{tabular}{|c|c|c|c|c|c|c|c|c|c|}
\hline Tratamento & $\begin{array}{c}\text { Temperatura } \\
\left({ }^{\circ} \mathrm{C}\right)\end{array}$ & Controle & & Água & & Ácido & & Lixa & \\
\hline \multirow{3}{*}{$\begin{array}{l}\text { Recém- } \\
\text { coletadas }\end{array}$} & $25(12 / 12)$ & $20,0 \pm 4,0$ & $\mathrm{BCa}$ & $21,0 \pm 5,0$ & $\mathrm{BCab}$ & $25,0 \pm 7,6$ & $\mathrm{Bb}$ & $88,0 \pm 3,7$ & $\mathrm{Aa}$ \\
\hline & $20-30(12 / 12)$ & $10,0 \pm 2,3$ & $\mathrm{Cb}$ & $26,0 \pm 4,3$ & $\mathrm{Ba}$ & $27,5 \pm 7,9$ & $\mathrm{Bb}$ & $89,0 \pm 4,8$ & Aa \\
\hline & $35(12 / 12)$ & $23,5 \pm 6,8$ & $\mathrm{Ca}$ & $27,0 \pm 5,0$ & $\mathrm{Ca}$ & $48,5 \pm 5,5$ & $\mathrm{Ba}$ & $87,0 \pm 3,8$ & $\mathrm{Aa}$ \\
\hline \multirow[t]{4}{*}{ Armazenadas } & $30(0 / 24)$ & $10,0 \pm 5,4$ & $\mathrm{Bb}$ & $11,0 \pm 1,2$ & $\mathrm{Bc}$ & $9,0 \pm 3,5$ & $\mathrm{Bc}$ & $78,0 \pm 9,4$ & $\mathrm{Aa}$ \\
\hline & $25(12 / 12)$ & $11,0 \pm 2,6$ & $\mathrm{Bb}$ & $8,0 \pm 2,8$ & $\mathrm{BCc}$ & $8,5 \pm 3,4$ & $\mathrm{Bc}$ & $88,0 \pm 7,2$ & $\mathrm{Aa}$ \\
\hline & $20-30(12 / 12)$ & $15,0 \pm 2,6$ & $\mathrm{Bab}$ & $10,5 \pm 4,4$ & $\mathrm{Bc}$ & $12,5 \pm 4,4$ & $\mathrm{Bc}$ & $88,0 \pm 7,8$ & Aa \\
\hline & $35(12 / 12)$ & $16,0 \pm 9,7$ & $\mathrm{Bab}$ & $16,0 \pm 2,8$ & $\mathrm{Bb}$ & $13,0 \pm 4,2$ & $\mathrm{Bc}$ & $86,0 \pm 7,1$ & Aa \\
\hline
\end{tabular}

Valores seguidos por letras distintas, maiúsculas nas linhas e minúsculas nas colunas, diferem entre si pelo Teste de Tukey. $(n=4 \times 50)$.

Foram observadas elevadas taxas de germinabilidade para as sementes submetidas à escarificação mecânica, de 78 a $89 \%$, as quais não diferiram significativamente entre as temperaturas e o 
tempo de armazenamento (Tabela 2). Esses valores são similares aos relatados por Dignart et al. (2005), que após submeterem as sementes ao escarificador elétrico por 10 e 15 segundos, obtiveram valores semelhantes de 80,8 e $83,3 \%$. Retirando parte do tegumento com o auxílio de um bisturi, Barradas e Handro (1974) obtiveram taxa de germinação entre 94 e 98\%, valores superiores aos encontrados neste trabalho.

A porcentagem de germinação foi inferior aos resultados encontrados no teste de tetrazólio. Isso porque esse teste revela somente as características dos tecidos do embrião, não considerando as influências externas sobre as sementes, de modo que esse teste pode apresentar resultados maiores (CATIE, 2000).

Os resultados apontam que a faixa ótima de germinação para as sementes de $S$. adstringens está entre 25 e $35^{\circ} \mathrm{C}$, conforme já relatado por Barradas e Handro (1974), que observaram uma faixa ótima de germinação entre 26 e $34^{\circ} \mathrm{C}$.

O índice de velocidade de germinação (IVG) das sementes do grupo controle foi, em geral, inferior quando comparado ao dos grupos submetidos aos tratamentos de superação de dormência (Tabela 3), e significativamente diferente entre as sementes recém-coletadas e as armazenadas, exceto na temperatura $20-30{ }^{\circ} \mathrm{C}$. Quando comparamos o tratamento controle e a imersão em água a $70{ }^{\circ} \mathrm{C}$, os valores foram estatisticamente semelhantes, exceto para a temperatura de $20-30{ }^{\circ} \mathrm{C}$ para as sementes recém-coletadas. Porém, entre estas e as armazenadas, esses valores foram estatisticamente semelhantes (Tabela 3). Para as sementes submetidas à escarificação química, o IVG foi significativamente semelhante em todas as temperaturas para as sementes recém-coletadas, quando comparadas com as sementes armazenadas. Quando comparamos o IVG entre as sementes recém-coletadas e as armazenadas, observamos uma diminuição significativa nesse parâmetro.

Os maiores valores de IVG foram encontrados para as sementes escarificadas mecanicamente. Foram observadas diferenças significativas entre as temperaturas somente para as sementes recémcoletadas, sendo a temperatura constante de $25^{\circ} \mathrm{C}$ a que apresentou o maior valor (Tabela 3). Os valores encontrados para o IVG foram significativamente diferentes entre as sementes recém-coletadas e as armazenadas (Tabela 3), indicando possivelmente uma perda de vigor das sementes após o armazenamento.

Embora tenham sido obtidos valores semelhantes para a porcentagem de germinação dentro de cada tratamento, o índice de velocidade de germinação foi significativamente superior nas sementes recém-coletadas, indicando que o armazenamento pode interferir na velocidade de germinação das sementes.

Tabela 3. Índice de velocidade de germinação (IVG) de sementes de S. adstringens, recém-coletadas e armazenadas por oito meses, submetidas a temperaturas constantes e alternadas (média \pm desvio padrão).

Table 3. Germination speed index of seeds of $S$. adstringens, freshly collected and stored for eight months, under constant and alternating temperatures (mean \pm standard deviation).

\begin{tabular}{|c|c|c|c|c|c|c|c|c|c|c|c|c|c|c|c|}
\hline \multirow{3}{*}{$\begin{array}{l}\text { Tratamento } \\
\begin{array}{l}\text { Recém- } \\
\text { coletadas }\end{array}\end{array}$} & \multirow{2}{*}{$\begin{array}{c}\text { Temperatura } \\
\left({ }^{\circ} \mathbf{C}\right)\end{array}$} & \multicolumn{3}{|c|}{ Controle } & \multicolumn{3}{|c|}{ Água } & \multicolumn{4}{|c|}{ Ácido } & \multicolumn{4}{|c|}{ Lixa } \\
\hline & & 2,4 & $\pm 0,3$ & $\mathrm{Ba}$ & 3,6 & $\pm 1,4$ & $\mathrm{Ba}$ & 4,9 & \pm 1 & 1,5 & $\mathrm{Ba}$ & 23,6 & \pm 5 & & Aá \\
\hline & & 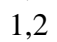 & $\pm 0,6$ & $\mathrm{Ch}$ & 5,0 & \pm 1 & $\mathrm{D}$ & 4,7 & \pm 1 & 1,6 & $\mathrm{Ba}$ & 15,6 & \pm & 7 & $\mathrm{Ab}$ \\
\hline \multirow{5}{*}{ Armazenadas } & & 2,4 & $\pm 0,4$ & $\mathrm{Ca}$ & 3,7 & $\pm 2,0$ & $\mathrm{BCa}$ & 6,4 & \pm 0 & 0,8 & $\mathrm{Ba}$ & 17,0 & \pm & 2,4 & Aal \\
\hline & 30 & 1,1 & $\pm 0,5$ & $\mathrm{Bb}$ & 0,7 & $\pm 0,3$ & $\mathrm{Bb}$ & 0,8 & \pm 0 & 0,3 & $\mathrm{Bb}$ & 10,7 & \pm & 1,5 & Ac \\
\hline & $25(1$ & 0 & $\pm 0,6$ & $\mathrm{Bb}$ & 0,6 & $\pm 0,2$ & $\mathrm{Bb}$ & 0,9 & \pm 0 & 0,3 & $\mathrm{Bb}$ & 11,6 & \pm 1 & 1,3 & $\mathrm{Ac}$ \\
\hline & $20-30(1)$ & ,5 & $\pm 0,3$ & $\mathrm{Bb}$ & 1,2 & $\pm 0,7$ & $\mathrm{Bb}$ & 1,1 & \pm 0 & 0,4 & $\mathrm{Bb}$ & 11,1 & \pm & 1,8 & Ac \\
\hline & $35(12 / 12)$ & 1,2 & $\pm 0,7$ & $\mathrm{Bb}$ & 1,6 & $\pm 0,6$ & $\mathrm{Bb}$ & 0,9 & \pm 0 & 0,3 & $\mathrm{Bb}$ & 10,5 & & 1,7 & Ac \\
\hline
\end{tabular}

Valores seguidos por letras distintas, maiúsculas nas linhas e minúsculas nas colunas, diferem entre si pelo Teste de Tukey. $(n=4 \times 50)$.

\section{Desenvolvimento inicial}

A taxa de sobrevivência dos indivíduos de $S$. adstringens, tanto sob o tratamento a pleno sol quanto sob sombreamento $50 \%$, foi, respectivamente, considerada alta, 65 e $75 \%$, respectivamente. Na literatura, é citado que taxas de sobrevivência superiores a $60 \%$ são consideradas altas (CORRÊA; 
CARDOSO, 1998; DURIGAN; SILVEIRA, 1999; SOUZA, 2002). Esses resultados indicam que essa espécie apresenta boa resposta à irradiação plena e deve ser incluída entre as espécies com alto potencial para a recuperação de áreas degradadas.

Aos seis meses de idade (junho/04), quando as plantas foram submetidas aos dois diferentes tratamentos, o diâmetro do coleto, a altura das plantas e o número de folhas não diferiram significativamente, indicando que as plantas apresentavam crescimento homogêneo quanto a essas variáveis (Tabela 4). Os indivíduos apresentaram pequeno incremento no diâmetro do coleto e seus valores médios não apresentaram diferenças significativas entre os tratamentos durante todo o período do experimento.

Para a variável altura, durante o período da seca e o início da estação chuvosa, os indivíduos apresentaram respostas diferenciadas entre os tratamentos, com valores médios significativamente superiores na condição de $50 \%$ de sombreamento. Contudo, durante a estação chuvosa, as médias foram similares entre os tratamentos, exceto para 52 e 60 semanas de idade das plantas.

Tabela 4. Efeito dos diferentes níveis de sombreamento sobre as variáveis diâmetro do coleto (mm), altura $(\mathrm{cm})$ e número de folhas, em diferentes idades das plantas de $S$. adstringens.

Table 4. Effect of different levels of shading on the variables base stem diameter $(\mathrm{mm})$, height $(\mathrm{cm})$ and number of leaves, at different ages of S. adstringens.

\begin{tabular}{|c|c|c|c|c|}
\hline Idade das plantas (semanas) & Tratamento & $\begin{array}{c}\text { Diâm. coleto } \\
(\mathrm{mm})\end{array}$ & Altura (cm) & $\begin{array}{c}\begin{array}{c}\text { Número de } \\
\text { folhas }\end{array} \\
\end{array}$ \\
\hline 24 & pleno sol & $1,33 \mathrm{a}$ & $1,83 \mathrm{a}$ & 2,90 \\
\hline Data: 04/06/04 & $50 \%$ & $1,42 \mathrm{a}$ & $2,09 \mathrm{a}$ & 3,05 \\
\hline 28 & pleno sol & $1,18 \mathrm{a}$ & $1,87 \mathrm{~b}$ & 4,32 \\
\hline Data: 02/07/04 & $50 \%$ & $1,28 \mathrm{a}$ & $2,35 \mathrm{a}$ & 4,45 \\
\hline 32 & pleno sol & $1,16 \mathrm{a}$ & $1,93 \mathrm{~b}$ & 5,50 \\
\hline Data: 30/07/04 & $50 \%$ & $1,25 \mathrm{a}$ & $2,42 \mathrm{a}$ & 5,40 \\
\hline 36 & pleno sol & $1,16 \mathrm{a}$ & $2,04 \mathrm{~b}$ & 6,78 \\
\hline Data: 27/08/04 & $50 \%$ & $1,28 \mathrm{a}$ & $2,62 \mathrm{a}$ & 6,55 \\
\hline 40 & pleno sol & $1,25 \mathrm{a}$ & $2,39 \mathrm{~b}$ & 8,00 \\
\hline Data: 24/09/04 & $50 \%$ & $1,38 \mathrm{a}$ & $3,15 \mathrm{a}$ & 8,05 \\
\hline 44 & pleno sol & $1,33 \mathrm{a}$ & $2,72 \mathrm{~b}$ & 8,22 \\
\hline Data: 22/10/04 & $50 \%$ & $1,49 \mathrm{a}$ & $3,45 \mathrm{a}$ & 6,70 \\
\hline 48 & pleno sol & $1,47 \mathrm{a}$ & $2,93 \mathrm{~b}$ & 7,28 \\
\hline Data: 19/11/04 & $50 \%$ & $1,64 \mathrm{a}$ & $3,58 \mathrm{a}$ & 5,95 \\
\hline 52 & pleno sol & $1,37 \mathrm{a}$ & $2,90 \mathrm{~b}$ & 3,76 \\
\hline Data: 17/12/04 & $50 \%$ & $2,39 \mathrm{a}$ & $3,81 \mathrm{a}$ & 4,20 \\
\hline 56 & pleno sol & $1,49 \mathrm{a}$ & $2,91 \mathrm{a}$ & 2,73 \\
\hline Data: 14/01/05 & $50 \%$ & $1,75 \mathrm{a}$ & $3,59 \mathrm{a}$ & 3,78 \\
\hline 60 & pleno sol & $1,30 \mathrm{a}$ & $2,50 \mathrm{~b}$ & 2,46 \\
\hline Data: 29/01/05 & $50 \%$ & $1,75 \mathrm{a}$ & $3,71 \mathrm{a}$ & 3,56 \\
\hline 64 & pleno sol & $1,27 \mathrm{a}$ & $2,26 \mathrm{a}$ & 2,25 \\
\hline Data: 26/02/05 & $50 \%$ & $1,62 \mathrm{a}$ & $3,29 \mathrm{a}$ & 3,87 \\
\hline 68 & pleno sol & $1,19 \mathrm{a}$ & $2,08 \mathrm{a}$ & 2,18 \\
\hline Data: 26/03/05 & $50 \%$ & $1,66 \mathrm{a}$ & $3,29 \mathrm{a}$ & 3,73 \\
\hline
\end{tabular}

Valores seguidos por letras distintas nas colunas diferem entre si pelo Teste de Tukey.

As espécies lenhosas do cerrado, devido à sazonalidade climática observada nesse bioma, têm um período de sete a oito meses para o estabelecimento de suas plântulas até o início da estação seca (FRANCO, 2005).

Cabe ressaltar que essa espécie pode ser classificada como heliófita, ocorrendo predominantemente em ambientes abertos, e possui capacidade de rebrota. Assim, recomenda-se a utilização de $S$. adstringens, em conjunto com espécies de crescimento rápido, nas fases iniciais de programas de recuperação de áreas de cerrado. Os resultados obtidos neste trabalho poderão subsidiar o delineamento de ações necessárias para o manejo e conservação de $S$. adstringens. 


\section{CONCLUSÕES}

- Sementes de $S$. adstringens são afotoblásticas, apresentam faixa ótima de germinação entre 25 e $35^{\circ} \mathrm{C}$ e dormência por impermeabilidade do tegumento, superada, eficientemente, pela escarificação mecânica.

- A conservação das sementes ex situ, por pelo menos oito meses, pode ser feita por armazenamento em refrigerador $\left(5-9^{\circ} \mathrm{C}\right)$.

- Plantas de S. adstringens não apresentam diferenças nas taxas de sobrevivência, diâmetro do coleto e altura da parte aérea, em condições ambientais de pleno sol e sombreamento de $50 \%$.

\section{AGRADECIMENTOS}

Os autores agradecem à FAPEMIG, pelo auxílio financeiro e concessão de bolsa para Fabrícia Pena Viegas e Renata de Melo Ferreira Lopes.

\section{REFERÊNCIAS}

AGUIAR, F. F. A.; KANASHIRO, S.; TAVARES, A. R.; PINTO, M. M.; STANCATO, G. C.; AGUIAR, J.; NASCIMENTO, T. D. R. Germinação de sementes e formação de mudas de Caesalpinia echinata Lam. (pau-brasil): efeito de sombreamento. Revista Árvore, Viçosa, v. 29, n. 6, p. 871 - 875, 2005.

ALMEIDA, S. P.; PROENÇA, C. E. B.; SANO, S. M.; RIBEIRO, J. F. Cerrado: espécies vegetais úteis. Planaltina: EMPRAPA-CPAC, 1998, 464 p.

ARRIGONI-BLANK, M. F.; CARVALHO, D. A.; ALVARENGA, A. A.; LAURA, V. A.; BLANK, A. F. Fenologia e germinação de guariroba (Campomanesia pubescens (DC.) Berg.): espécies de Cerrado. Ciência e Agrotecnologia, Lavras, v. 21, n. 2, p. 237 - 241, 1997.

BARRADAS, M. M.; HANDRO, W. Algumas observações sobre a germinação da semente do barbatimão, Stryphnodendron barbadetimam (Vell.) Mart. (Leguminosae-Mimosoideae). Boletim de Botânica, São Paulo, v. 2, p. 139 - 150, 1974.

BASKIN, C. C.; BASKIN, J. M. Seeds: ecology, biogeography and evolution of dormancy and germination. San Diego: Academic Press, 1998. 666 p.

BORGES FILHO, H. C.; FELFILI, J. M. Avaliação dos níveis de extrativismo da casca de barbatimão [Stryphnodendron adstringens (Mart.) Coville] no Distrito Federal, Brasil. Revista Árvore, Viçosa, v. 27, n. 5, p. 735 - 745, 2003.

BRANDÃO, M.. Plantas produtoras de tanino nos cerrados mineiros. Informe Agropecuário, Belo Horizonte, v. 16, n. 173, p. 33 - 35, 1992.

BRASIL. MINISTÉRIO DA AGRICULTURA. SECRETARIA NACIONAL DE DEFESA AGROPECUÁRIA. Regras para análise de sementes. Brasília: SNDA/DNDV/CLAV, 1992. 365 p.

CENTRO AGRONÓMICO TROPICAL DE INVESTIGACIÓN Y ENSEÑANZA (CATIE). Proyecto de Semillas Forestales. Laboratorio para analizar de 2000 a 5000 muestras de semillas. Danida Forest Seed Centre, Costa Rica, 2000. 99 p.

CORRÊA, R. S.; CARDOSO, E. S. Espécies testadas na revegetação de áreas degradadas. In: CORRÊA, R. S.; MELO FILHO, B. (Orgs.). Ecologia e recuperação de áreas degradadas no cerrado. BrasíliaDF: Paralelo 15, 1998. p. $101-116$.

CRUZ, E. D.; MARTINS, F. O. M.; CARVALHO, J. E. U. C. Biometria de frutos e sementes e germinação de jatobá-curuba (Hymenaea intermedia Ducke, Leguminosae-Cesalpinioideae). Revista Brasileira de Botânica, São Paulo, v. 24, n. 2, p. 161 - 165, 2001. 
DIGNART, S.; FERRONATO, A.; CAMARGO, I. P.; MENDONÇA, E. A. F. Superação de dormência física em sementes de barbatimão (Stryphnodendron adstringens (Mart.) Coville). Revista Brasileira de Plantas Medicinais, Botucatu, v. 7, n. 2, p. 1 - 6, 2005.

DURIGAN, G.; SILVEIRA, E. R. Recomposição da mata ciliar em domínio de cerrado, Assis, SP. Scientia Forestalis, Piracicaba, n. 56, p. 135 - 144, 1999.

FELFILI, J. M.; SILVA JÚNIOR; M. C.; DIAS, B. J. REZENDE, A. V. Estudo fenológico de Stryphnodendron adstringens (Mart.) Coville no cerrado sensu stricto da Fazenda Água Limpa no Distrito Federal, Brasil. Revista Brasileira Botânica, São Paulo, v. 22, n. 1, p. 83 - 90, 1999.

FIRETTI, F. Biologia reprodutiva e polinização de Stryphnodendron adstringens (Mart.) Coville (Leguminosae-Mimosoideae). 89 f. Dissertação (Mestrado Botânica) - Universidade de Brasília, Brasília, 2001.

FRANCO, A. Biodiversidade de forma e função: implicações ecofisiológicas das estratégias de utilização de água e luz em plantas lenhosas do Cerrado. In: SCARIOT, A.; SOUZA-SILVA, J. C.; FELFILI, J. M. (Orgs.) Cerrado: ecologia, biodiversidade e conservação. Brasília: Ministério do Meio Ambiente, p. 179 - 196. 2005.

GUARIM NETO, G.; MORAIS, R. G. Recursos medicinais de espécies do Cerrado de Mato Grosso: um estudo bibliográfico. Acta Botanica Brasilica, São Paulo, v. 17, n. 4, p. 561 - 584, 2003.

JOLY, C. A.; FELIPPE, G. M. Dormência das sementes de Rapanea guianensis Aubl. Revista Brasileira de Botânica, São Paulo, v. 2, n. 1, p. 1 - 6, 1979.

KISSMANN, C. Fisiologia da germinação de sementes e morfoanatomia do foliólulo de espécies de Stryphnodendron Mart. 117 f. Dissertação (Mestrado em Agronomia - Produção Vegetal) - Universidade Federal da Grande Dourados, Dourados, 2008.

LABOURIAU, L. G. A germinação das sementes. 173 f. Monografia (Monografias Científicas) Secretaria-Geral da Organização dos Estados Americanos, Programa Regional de Desenvolvimento Científico e Tecnológico, Washington, 1983.

LEDO, A. A. M. Estudo da causa da dormência em sementes de guapuruvu (Schizolobium parahybum (Vell.) Blake) e orelha-de-negro (Enterolobium contortisiliquum (Vell.) Morong) e método para sua quebra. 57 f. Dissertação (Mestrado em Fisiologia Vegetal) - Universidade Federal de Viçosa, Viçosa, 1977.

LINS, V. S.; ANTON, C. S.; MISSIO, R. F.; BALERONI, C. R. S.; SILVA, A. M.; CAMBUIM, J.; MORAES, M. L. T. Recomposição de Stryphnodendron adstringens e diversidade de espécies vegetais em área degradada, Selvíria, MS. In: SIMPÓSIO NACIONAL SOBRE RECUPERAÇÃO DE ÁREAS DEGRADADAS, 5., 2002, Belo Horizonte. Anais... Belo Horizonte: Sociedade Brasileira de Recuperação de Áreas Degradadas, 2002. p. 108 - 110.

LISBOA, M. S.; FERREIRA, S. M.; SILVA, M. S. Uso de plantas medicinais para tratar úlceras e gastrites. Sitientibus, Série Ciências Biológicas, Feira de Santana, v. 6, n. Especial - Etnobiologia, p. 13 20, 2006.

MARTINS, C. C.; MACHADO, C. G.; NAKAGAWA, J. Temperatura e substrato para o teste de germinação de sementes de barbatimão (Stryphnodendron adstringens (Mart.) Coville (Leguminosae). Revista Árvore, Viçosa, v. 32, n. 4, p. 633 - 639, 2008.

MARTINS, C. C.; NAKAGAWA, J. Germinação de sementes de Stryphnodendron adstringens (Mart.) Coville de diferentes origens submetidas a tratamentos para superação de dormência. Revista Árvore, Viçosa, v. 32, n. 6, p. 1059 - 1067, 2008.

MELHEM, T. S. Fisiologia da germinação das sementes de Dipteryx alata Vog. (LeguminosaeLotoideae). Hoehnea, São Paulo, v. 5, p. 59 - 90, 1975. 
MELO, J. T.; SILVA, J. A.; TORRES, R. A. A.; SILVEIRA, C. E. S.; CALDAS, L. S. Coleta, propagação e desenvolvimento inicial de espécies do Cerrado. In: SANO, M. S.; ALMEIDA, S. P. Cerrado: ambiente e flora. Planaltina, 1998. p. 193 - 243.

MIRANDA, A. R. Fenologia, Aspectos Ecofisiológicos da Germinação e Conservação de Sementes de Plathymenia reticulata Benth. Fabaceae-Mimosoideae. 183 f. Tese (Doutorado em Ecologia e Recursos Naturais) - Universidade Federal de São Carlos, São Carlos, 1999.

MITTERMEIER, R. A.; GIL, P. R.; HOFFMANN, M.; PILGRIM, J.; BROOKS, T.; MITTERMEIER, C. G.; LAMOUREX, J.; FONSECA, G. A. B. Earth's biologically richest and most endangered terrestrial ecorregions. Disponível em: <http://multimedia.conservation.org/cabs/online_pubs/hotspots2/ introduction.htm>. Acesso em: 07/10/2008.

MORS, W. B.; RIZZINI, C. T. Useful plants of Brazil. Amsterdam: Holdeu-Day, 1966. 166 p.

PARRON, L. M.; RIBEIRO, J. F.; MARTINEZ, L. L. Revegetação de uma área degradada no córrego Sarandi. Boletim do Herbário Ezequias Paulo Heringer, Brasília, v. 5, p. 88 - 102, 2000.

POPINIGIS, F. Fisiologia de sementes. Brasília: AGIPLAN, 1977. 288 p.

RATTER, J. A.; RIBEIRO, J. F.; BRIDGEWATER, S. The Brazilian Cerrado vegetation and threats to its biodiversity. Annals of Botany, Oxford, v. 80, p. 223 - 230, 1997.

REIS, M. S.; MARTINS, P. S. Avaliação do grau de dormência das sementes de espécies de Stylosanthes Sw. Revista Ceres, Viçosa, v. 26, n. 206, p. 357 - 364, 1989.

REZENDE, A. V.; FELFILI, J. M. Avaliação do estoque de carbono no cerrado sensu stricto do Brasil Central. Comunicações Técnicas Florestais 6. Universidade de Brasília, Departamento de Engenharia Florestal. 28 p. 2004.

REZENDE, A. V.; KONDO, M. K. Leguminosas e recuperação de áreas degradadas. Informe Agropecuário, Belo Horizonte, v. 22, n. 210, p. 46 - 56, 2001.

RIZZINI, C. T. Tratado de fitogeografia do Brasil: aspectos ecológicos, sociológicos e florísticos. Rio de Janeiro: Âmbito Cultural Edições, 2. ed. 1997. 747 p.

RODRIGUES, E. H. A.; AGUIAR, I. B.; SADER, R. Quebra de dormência de sementes de três espécies do Gênero Cassia. Revista Brasileira de Sementes, Brasília, v. 12, n. 2, p. 17 - 27, 1990.

SILVA, J. C.; FELIPPE, G. M. Germination of Stylosanthes macrocephala. Revista Brasileira de Botânica, São Paulo, v. 9, n. 2, p. 263 - 268, 1986.

SOUZA, C. C. Estabelecimento e crescimento inicial de espécies florestais em plantios de recuperação de Matas de Galeria do Distrito Federal. 91 f. Dissertação (Mestrado em Engenharia Florestal) - Universidade de Brasília, Brasília, 2002.

ZAR, J. H. Biostatistical Analysis. New Jersey: Prentice-Hall, 4 ed. 1999. 662 p. 
